\title{
Has Parenting Changed over Past Decade? A Qualitative Study of Generational Shifts in Parenting
}

\author{
Ching-Man Lam, Wai-Man Kwong, and Siu-Ming To
}

\begin{abstract}
Although the importance of taking a historical perspective in understanding a phenomenon has been well-recognized, attempt to study generational shifts in parenting is almost non-existent in Hong Kong. Contemporary parenting is characterized as fraught with problems - anxieties about children's well-being and one's own adequacy as a parent and worries about adverse consequences of parenting on one's children. Rhetoric abounds, such as "irresponsible parenting", "overprotective parenting", "anxious parents", "helicopter parents", and "monster parents". Such vernaculars are frequently found in the mass media sounding alarm over the state of contemporary parenthood. However, there are only few studies tracing how contemporary parenthood has come to be characterized as such. In retrospect as practitioners and researchers, we reckon that certain generational shifts in "themes" of parenthood are discernible. This study seeks to unravel these generational shifts in parenthood in the recent history of Hong Kong evolving into modern city. This study covered discourse analysis of $\mathbf{4 8}$ sampled items of primers on parenting and parent education resource materials, and 120 life story interviews with 60 parents, each being interviewed individually twice. The respondents were recruited to represent five parent-cohorts -first-time parents in the 1970's or before, in the 80's, in the 90's, in the 2000's and in the 2010's. Each parent-cohort was made up of 6 mothers and 6 fathers, giving a total sample of 30 mothers and 30 fathers. Reporting our preliminary findings, this paper explores generational shifts in parenting discourse and people's experience of parenthood over the past decades and examines how contextual factors and discursive formations promoted by parenting professionals have shaped and re-shaped parenting in Hong Kong in the past five decades.
\end{abstract}

Index Terms-Generational difference, parenting, parenthood, parental responsibility.

\section{INTRODUCTION}

How has parenting in Hong Kong changed over the past five decades? Has the quality of parenting advanced or regressed? If indeed there were generational shifts in parenting, did changes in cultural and contextual factors contribute to such, and if so, how? Would changes in parenting practice contribute to the rise in developmental problems in childhood and adolescence? How did older-generation parents "do" parenting? What do we learn from the past to furnish local pointers for future generations

Manuscript received February 18, 2019; revised May 1, 2019. This study was financially supported by the General Research Fund 2014/15 of the Research Grant Council, The Hong Kong SAR Government (Ref No. U414053)

C. M. Lam and S. M. To are with the Department of Social Work of The Chinese University of Hong Kong, Hong Kong (e-mail: cmlam@swk.cuhk.edu.hk, smto@swk.cuhk.edu.hk).

W. M. Kwong is with the Hong Kong Professional Counselling Association, Hong Kong (waimankwong618@gmail.com). of parents? To answer these questions, we need to re-visit parenthood in the bygone era. Being researchers and practitioners in parent education, we have witnessed significant, even paradigmatic changes in parenting in Hong Kong over the past five decades. These changes were attendant by fast cultural, social, economic, and demographic changes. Contemporary parenthood is characterized as one fraught with problems, complicated by parents' anxieties about children' well-being, and their self-doubt and self-blame about their adequacy in childrearing [1]-[3]. "Irresponsible parenting", "overprotective parenting", "anxious parents", "helicopter parents" constantly monitoring children's lives, and "monster parents", are common-place terms in the mass media's portrayal of contemporary parenthood. However, no study (as far as we know) has attempted to discern and track historical antecedents to the present characterization of contemporary parenthood. How did "talks" about parenthood - dominant discourses shaping the way people think and act as parents change with the passage of time? Little is known about how parents and parenting are turned into discourse objects and how professional infiltrated the private domain of parenthood by depicting parents as both the source and solution of childhood problems. This study aims to dissect parenthood in Hong Kong and to investigate how the interplay between history and context led to generational shifts in parenting.

\section{BACKGROUND}

In the past few decades, there has been a surge in research studies on parenting, including local studies [4]-[7]. Over the past 35 years, research based on Baumrind's [8] conceptualization of parenting style has produced a remarkably consistent picture of the parenting style found to be conducive to successful socialization of children into the dominant culture. In the Millennium era, there is a growing concern of the phenomenon being variously characterized as "overparenting" [9], [2] "overprotective parenting" [10], [11], "monster parenting"[12], and "helicopter parenting" [3]. However, there is a paucity of local research examining the phenomenon of generational shifts in parenting in Hong Kong.

It is well noted that the values parents hold and the goals toward which they socialize their children are critical determinants of parenting behaviours [13], [14]. People's values and beliefs about their roles and responsibilities as parents determine their naturally occurring behaviours [8]. However, extant empirical work investigating parental beliefs has focused narrowly on specific beliefs. The bulk of studies investigated the effects of parental beliefs on children's cognitive development, particularly academic 
achievement and social development. Only a few studied intergenerational transmissions of values and beliefs [15]. There has been no study on generational shifts of parental beliefs and practices in the Hong Kong context.

Researchers studying the Chinese family have identified distinctive features of Chinese parenting [16]-[18]. The number of studies on parenting in Chinese culture, particularly parenting practice in Mainland China, has increased substantially in recent years. However, using mainstream Western concepts and measures to study Chinese parenting has been the dominant trend. Such an approach is undermined by inherent deficiency arising from ethnocentric bias and is being discredited for imposing Western conceptual categories on non-Western cultures [19], in disregard of cultural irrelevance of Western constructs[17], [20].

Researchers in the West have begun to recognize the importance of taking a historical perspective in understanding a phenomenon. They have attempted to study historical trends of parenting. A UK study - Time trends in parenting and outcomes for young people - reviewed various aspects of social change impinging on parenting practices and consequently adolescent experiences, looking for ways to improve outcomes for young people [21]. Historical shifts in ideas about rearing infants and young children [22], content changes in parent education books [23], and differing parental effort to learn parenting [24] have also been investigated in the United States. As parenting in Hong Kong has been undergoing changes, we envisage that parenting practice in the 1970s likely differed from that in the 1990s, and the latter differed from nowadays' parenting practice. However, as yet there is no study tracing such changes. Very little is known about patterns of change in parenting.

Literature review reveals several studies on parenting and parent education in Hong Kong, notably studies on family variables influencing children's developmental outcomes. Research findings point to the significant role of parenting styles and family functioning in determining children's school achievement and psychological adjustment [25], [26]. There has been increasing attention directed to young people's perception of their families and adolescents' subjective evaluation of parental psychological and behavioural control [27]. There were studies on parental stress and anger [28]-[30]. On the whole, these studies were plagued by methodological criticisms, notably invalidity of Western conceptual categories [31], [19] and cultural irrelevance of Western constructs [17], [20]. Other criticisms include assuming a unidirectional attitude-behaviour relation, viewing childrearing attitudes as static [32], and reliability issues of behavioural self-reports [33]. Given the research gap identified, the present study incorporates both context and history as key parameters in the investigation of generational shifts in parenting in Hong Kong over a span of five decades. We sought to discern temporal patterns of generational shifts in how people think and act as parents and to uncover changing contextual factors that account for these changes.

\section{Methodology}

We adopted qualitative research methods to uncover the subjective view of parents, because there was a paucity of qualitative study for gaining in-depth understanding of parenting in Hong Kong. The research process started with a discourse analytic study (the first component of a mixed method research design) to track temporal changes (if any) of dominant social/professional discourses on parenting as a contextual background for analysing narrative accounts of parenthood (the second component). We aimed at ascertaining discoursal changes as a major contextual variable having bearing on parenting. The Family Life Education Resource Center set up by the Hong Kong government in 1979 to spearhead programmatic parent education effort collected a large archive of books, professional writings on parenting, research and programme reports, and resource materials for aiding professional-led parent education. After screening the corpus of collected items, we selected 1,365 relevant items to form the sampling frame. These items were then grouped into 30 sub-categories. A purposeful sample of 48 items were methodically selected based on the principle of maximizing diversity in terms of media-type, content category and topic, author and author background, temporal dispersion by publication or production years, and lastly user popularity. The sampled items were then discourse analysed in the CDA tradition.

The second component was a narrative inquiry of people's experience of parenthood, meanings they conferred to parenthood and parental identity construction. Participants were recruited by multiple means to represent each of the following five parent-cohorts: first-time parents in the 1970's or before, in the 80 's, in the 90 's, in the 2000 's and in the 2010s. There were six mothers and six fathers in each parent-cohort, with an even mix of "high", "middle" and "low" socioeconomic backgrounds, yielding a sample of 30 mothers and 30 fathers. Narrative inquiry is a research method accessing people's narrative construction of lived experience and meaning-making of the experience told. We adopted the life story interview as the data collection method to capture the participants' stories of significant life events in parenthood [34]-[37]. Embedded in a person's life narrative of being and becoming a parent is the person's ideology, beliefs, values, and identity as a parent. They are discernible in the light of what and how the person storied parenthood and the meaning they conferred to their storied experiences.

Each participant was interviewed individually twice, yielding a total of 120 interviews. The first interview is a life story interview aiming at gathering a participant's experience of parenthood. In the process of life story telling, a person engages in "reflection on events and experiences that the teller may not have thought about fully" [38]. The interview began with the participant storying her/his experience of parenthood in those days. The participant was asked to story her/his development as a parent, review "critical events" and "difficulty episodes" in parenting and reflect on environmental contingencies that parents of her/his generation often faced in discharging the parental role. The second interview began with a "member check" of the researchers' re-presentation and analysis of the story told in the first interview, followed by probes to uncover parental beliefs underpinning parenting practice and action schema underlying the participant's approach to parenting. Both interviews followed a semi-structured interview protocol. Each interview lasted for approximately 90 minutes. 
All interviews were audio-taped and transcribed. Interview data were analysed with NVivo. Analyses of data followed Riessman's [37] poetic structure and Glaser \& Strauss' [39] grounded theory approach of coding, category construction and thematic analysis to map meaning, theme and context in the storied content. Both within- and cross-cohort analysis were pursued to identify cohort-specific themes as well as temporal continuities and discontinuities in social construction of parenthood.

\section{Findings - Discourse ANALYTIC STUdy}

A descriptive discourse analysis was performed on the 48 sampled discoursal materials to arrive at the following 17 thematic domains: 1) societal demand on parents; 2) parenting knowledge is culturally transmitted accumulated wisdom; 3) developmental theories inform proper parenting; 4) competing epistemologies of parenting knowledge; 5) epistemic authority of parenting experts; 6) parenting knowledge becomes an expert-dominated knowledge discipline; 7) parental nurturance determines long-term child outcome; 8) children's future success becomes the valued goal of parenting; 9), problematizing parenthood; 10) parents learn from experts; 11) experts provide effective methods of parenting; 12) parenting is a skilled practice; 13) professional dominance; 14) modern child-centered parenting; 15) the success of professional effort to market parenting information and parent educations; 16) a growing consumer market of parenting information; and lastly 17) pedagogical development in parent education. Of these 17 themes, two dominant themes, namely "problematizing parenthood" and "expert domination over parenting" deserve further elaboration here, as they provoked a reflexive examination of our professional role in shaping the ecology of contemporary parenthood and how parent empowerment through parent education has inadvertently resulted in parent disempowerment.

\section{A. Problematizing Parenthood and Expert Domination}

Increasingly, parenting has been described as fraught with problems. The bulk of sampled discoursal materials were mostly indigenous publications (e.g. primers on parenting) or video resources for conducting parent education (e.g. television series on parenting) published/produced in the 1990s and after. Consistently, they converged on a negative focus of people's parenthood experience. Parenting difficulties were portrayed as a necessary evil in contemporary parenthood because traditional parenting (being characterized as "authoritarian") no longer works ("because time has changed") and may even be harmful to children (e.g. disciplining children by coercive actions, including physical punishment). In addition, it was asserted that parenting is a knowledge discipline, and that proper parenting should be informed by scientific knowledge (e.g. child psychology, child development theory), which is not known but now available to parents. Thus, parenting difficulties were explained away as symptomatic of parental inadequacy and unrealistic expectations due to their ignorance of scientific parenting knowledge. This dictum pronounced the failure of cultural transmission to prepare people for the modern parental role - taken by us to be a consequence of detraditionalization in late modernity. While traditional parenting emerged as something natural, modern parenting required intensive parental nurturance in order to give one's children an edge over others in leading a successful adulthood. In other words, new generations of parents are subject to ever-growing societal demand on them to invest on childrearing in an intensive nurturing way. Government-funded, professional-led parent education thus emerged as a form of parent support while parents, particularly first-time parents, were expected to learn from experts. In summary, problematizing parenthood was a fallout of the detraditionalization process as Hong Kong progressed to late modernity. In lieu of the guidance of tradition and being ignorant of scientific parenting knowledge, younger-generation parents necessarily face parenting difficulties (presumably) arising from their inadequacy. As a dominant discourse propagated by parenting professionals, the 'problematizing parenthood' discourse in turn legitimized professional regulation of parenting through education and knowledge dissemination, thus in turn advancing the 'market project' of parenting professionals and turning parenting into a pseudo-professional practice (as effective parenting involves applying expert knowledge and skills). Thus, expert domination in the domestic sphere of parenting matured, as the public accepted the notion that parenting is a knowledge discipline. Younger-generation parents are too anxious now that they are motivated to learn from experts. Thence, parent education is now a form of parent support as well as a tool of professional subjugation of parents.

\section{FINDINGS — LIFE STORY RESEARCH}

\section{A. Expanding Scope of Parental Responsibility}

Our thematic analysis of the parenthood stories collected from the 60 participants arrived at two major themes that corroborated with the findings of the discourse analytic study, namely, "expanding scope of parental responsibility" and "parental nurturance determines child outcome". Participants across the 5 parent-cohorts converged on the view that there has been an ever-increasing societal demand on parents, as a primary parental responsibility, in providing their best nurturance to children. This is a sentiment widely shared among the participants, as expressed in a participant's remark that "this is your children, you're by all means obliged to be responsible." There is also a growing anxiety among younger-generation parents, arising from their insecurity with their own adequacy in providing proper parenting to children. For one thing, parenting professionals advise them that parents often inadvertently commit mistakes, thus hampering child development even if they are unaware of this. For the other, there is no reliable way for them to 'do' parenting properly, not only out of the concern of causing no harm to children, but also the parental responsibility of ensuring children's future well-being.

Both younger- and older-generation parents considered parental responsibility almost self-evident. Once a person becomes a parent, s/he should be able to immediately take up parental responsibility. Yet how parents define and discharge 
parental responsibility varied generation by generation. In comparison to older-generation parents, younger-generation parents exhibit a stronger awareness of their parental role and drive themselves harder to fulfil their parental responsibilities. For example, parents of the 1970s generally took an intuitive approach to perform parental duties. They followed folkways of parenting. However, two decades later, parents in the 1990s approached parenting as a knowledge-informed practice, which they need to learn from parenting experts.

Moving into 2010s, parents actively sought expert knowledge and advice on techniques and methods for effective parenting. The scope of parental responsibility also extended to go beyond what were expected of parents in the 1970s era: providing the essentials, such as food, shelter, tangible needs, daily care of the young, and basic schooling. Beginning from the 1980s (when Hong Kong's economy had lifted off), parental responsibility gradually expanded to include all-round parental guidance and nurturance of children. The younger-generation parents (from the 1990s till now) talked about cultivation of children, arranging early training for children to enhance their life opportunities for future success, enhancing children's capacity in emotional management (after the popularization of the concept of 'emotional intelligence') and tending to the quality of parent-child relationship. In a nutshell, there were increasing self-imposed demands and, consequently, self-doubt and self-blame among younger-generation parents, as they held themselves chiefly responsible for children's failure or success.

\section{B. Parental Nurturance Determines Child Outcome}

Parallel with the expanding scope of parental responsibilities was an obvious shift in parental beliefs about their leverage in controlling child outcomes. Among older-generation parents, they attributed child outcome largely to children's effort, and left the rest to destiny. How children would become in their grown-up years was out of parents' control. A father of the 1970s parent-cohort offer the view that "the nature of children is innately determined. Worm is born to be worm; dragon is born to be dragon". Such a fatalistic orientation became increasingly rare among younger-generation parents. The latter believed that parents should held themselves responsible for the success or failure of their children not only in the short-term but also long-term. Moreover, they believed that parental resource investment could enhance children's life opportunities, and quality parenting and nurturance would weigh heavily as a major determinant of child outcomes. A mother of the 1990s parent-cohort sought to "give the best to them [her children], with all my resources to nurture them". A father of the $2010 \mathrm{~s}$ parent-cohort said, "giving them [his children] what they want is not enough, I grow with them as well and I should take care of both tangible and intangible aspects [of children's life]". Among the younger-generation parents, there was a commonly held belief that parental resource investment, giving young children an early start, developing multiple abilities in children, all contribute to children's future success. Therefore, younger-generation parents hard-pressed themselves to try their very best to fulfil their nurturing role. Aspiring to maximize their children's potential and future well-being, parents sought to learn from parenting experts effective parenting methods and skills for better nurturing their children. Consequently, there opened an ever-expanding scope of parental responsibility as parenting professionals were only too eager to market their knowledge and skills. Contemporary generation of parents now subscribe to the 'nurture' assumption of the 'nature vs. nurture' debate in child development.

\section{DISCUSSION}

The discoursal materials examined in the discourse analytic study and the narrative inquiry of parenthood stories portrayed a deficit view of parents and parenting. Spotlighting problematic parenting practices, the parenting literature has promoted a "parent-blaming discourse", criticizing parental inadequacy and ignorance as the primary cause of parenting difficulties and negative child outcomes[40], [2]. The rally call of parenting professionals to market their service invariably faults parents. Thus, they are chiefly responsible for inducing in parents a heightened sense of anxiety, self-doubt and self-blame, as parents are unsure if the way they 'do' parenting may have caused adverse lifelong effects on their children [41]. Besides, modernization has led to a process of detraditionalization, such as the dismantling of traditional family norms and folk practices, thus exposing people to more choices and individual decision-making, all the while facing more uncertainties. In the case of parenting, there are many stressors and destabilizing factors in the wider societal context that have rendered parenting a site of conflict and tension. The pressure and anxiety associated with parenting are further exacerbated by the mass media and a growing commercial sector that sell their products and services by exploiting parental anxiety and guilt (for not giving the best to their children) [2], [42], [43]. As a result, commercialization of parenting information and advice rides on the professional-led parenting discourses and in return further widens the latter's circulation [41]. The prevailing parenting discourses pathologize traditional parenting and, by implication, the cultural imperatives it embodies. By conceiving parenting as a knowledge discipline and conferring epistemic authority to scientific and research-based knowledge, parenting professionals have turned parenting, originally a culturally transmitted folk practice, into a pseudo-professional practice. As such, parents need to learn and to be taught a more functional parenting style by knowledgeable professionals [44]. The propaganda calls of "learning from experts" and "learning to be better parents" offer hope and relief to parents, particularly first-time parents who are anxious about the demand of childrearing [45], [46]. Parent education is staged as a social intervention to ameliorate parental anxiety and guilt by offering the promise that learning expert knowledge and skills will help [42], [43].

With the inception of parent education as a major component of the newly created family life education service in Hong Kong in 1979, parenting professional started to take up the privileged position of being 'teachers' to parents. These parenting experts have succeeded in reconstructing people's visions and expectations of what parenting should be like [47]. Armed with their epistemic authority, parenting 
experts acquired the legitimacy for standard-setting and prescribing effective parenting methods and skills, as well as proper attitudes for parenting. Expert-prescribed principles and methods are characterized as new, effective ways of parenting, as they are grounded on a scientific rationality and their validity is expert-assured. The pronouncement that parents need expert advice and support is now widely accepted by the public. Under a consumerist capitalist framework, expert teachings and prescriptions usually adopt a middle-class stance and propagate a normative, standardized view of parenting that encourages parents to intervene more proactively in various aspects of children's life [47]. Foucault [48] contends that expert knowledge enmeshed with power and exercised through disciplinary mechanisms to regulate and control people. The knowledge claim of experts justifies their domination and expands their "professional market project" [49]. Being parent educators ourselves, we object to the present professional-dominated mode of parent education for its unintended consequence of breeding new generations of "anxious parent". We also call into question the ethics of professional regulation of parenthood [41]. If parent education is truly empowering, it should gear towards challenging dominant paradigms and hegemonic power and embraces diversity and inclusivity given the pluralism in parenting knowledge, parental goals and values. The mode of 'education' in parent education should no longer be 'depository' but should instead gear towards collaborative learning through sharing and scrutinizing experience-bound personal parenting knowledge [50], [51].

Our findings also reveal that "parental responsibility" has been intensified and widened in scope, including a broad range of tasks and demands (e.g. positioning a preschool child for school admission), emotional involvement, and 'resourcing' children for better life opportunities and future success. Our historical review of discoursal materials suggests that the Hong Kong Government has played an influential role in the "privatization" and "politicization" of parenting. Since the 1970 s, with the growing concern about a swelling government expenditure, the idea of small government came into dominance. At the same time, an "individualized needs" discourse took hold, arguing that the family, not the state, should play the most important role in fulfilling people's needs [52]. Looking into policy papers and public education campaigns [53], [54], [55], [56], [57] we conclude that the Hong Kong Government has taken multiple strategies to promote the significance of parenting in child development, making parental responsibility a key issue in policy formulation and public debate. A sustaining course of year-round publicity campaign featuring organized campaign activities, including parent education programmes, has been in place since 1979 (when the government-funded Family Life Education was established) to promote public awareness of the importance of family, highlighting in particular the centrality of parenting and parental responsibility.

The dual trends of individualization and privatization of parental responsibility now hold parents accountable for the well-being of the young generations, while playing down the role of the government in taking care of the young and giving support to the family. While we acknowledge the importance for people to fulfil their responsibilities as parents, we also advocate for taking a timely review of government responsibility and policies to support parents in raising children in a fast changing world, restoring a proactive governmental role, broadening the landscape of parent support and collective social responsibility for children. Afterall, children's well-being is a public good.

\section{REFERENCES}

[1] F. Furedi, Paranoid Parenting: Why Ignoring the Experts May Be Best for your Child, Chicago: Chicago Review Press, 2002.

[2] P. N. Steams, Anxious Parents: A History of Modern Childrearing in America, New York and London: New York University Press, 2003.

[3] M. K. Nelson, Parenting out of Control: Anxious Parents in Uncertain Times, New York and London: New York University Press, 2010.

[4] S. M. Chan, J. Bowes, and S. Wyver, "Chinese parenting in Hong Kong: Links among goals, beliefs and styles," Early Child Development and Care, vol. 197, no. 7, pp. 849-862, 2009.

[5] H. Fung, "Affect and early moral socialization: some insights and contributions from indigenous psychological studies in Taiwan," Indigenous and Cultural Psychology, Springer US, 2006.

[6] S. Lau, "Physical discipline in Chinese immigrant families: an adaptive culture perspective," Cultural Diversity and Ethnic Minority Psychology, vol.16, no. 3, pp. 313-322, 2010.

[7] C. McBride-Chang and L. Chang, "Adolescent-parent relations in Hong Kong: parenting styles, emotional autonomy and school achievement," The Journal of Genetic Psychology, vol. 159, no. 4, pp. 421-436, 1998.

[8] D. Baumrind, "Child care practices anteceding three patterns of preschool behavior," Genetic Psychology Monographs, vol. 75, pp. 43-88, 1967.

[9] J. Woodruff-Borden, C. Morrow, S. Bourland, and S. Cambron, "The behavior of anxious parents: examining mechanisms of transmission of anxiety from parent to child," Journal of Clinical Child and Adolescent Psychology, vol. 31, no. 3, pp. 364-374, 2002.

[10] M. Spokas and R .Heimberg, "Overprotective parenting, social anxiety, and external locus of control: Cross-sectional and longitudinal relationships," Cognitive Theory Research, vol. 33, pp. 543-551, 2009.

[11] M. Ungar, "Overprotective parenting: Helping parents provide children the right amount of risk and responsibility," The American Journal of Family Therapy, vol. 37, pp. 258-271, 2009.

[12] Wu. Hong Kong's pressure-cooker education system is producing 'monster parents'. [Online]. Available: https://www.scmp.com/comment/insight-opinion/article/2141621/ho ng-kongs-pressure-cooker-education-system-producing

[13] P. M. Symonds, "The psychology of parent-child relationships," New York: Appleton-Century-Crofts, 1939.

[14] S. M. Dornbusch, P. L. Ritter, P. H. Leiderman, D. F. Roberts, and M J. Fraleign, "The relation of parenting style to adolescent school performance," Child Development, vol. 58, pp. 1244-1257, 1987

[15] C. C. Yi, C. F. Chang, and Y. H. Chang, "The intergenerational transmission of family values: A comparison between teenagers and parents in Taiwan," Journal of Comparative Family Studies, vol. 35, no. 4, pp. 523-546, 2004.

[16] S. Lau, Growing up the Chinese way: Chinese child and adolescent development, Hong Kong: The Chinese University Press, 1996.

[17] R. Chao, "Beyond parental control and authoritarian parenting style: Understanding Chinese parenting through the cultural notion of training," Child Development, vol. 65, pp. 1111-1119, 1994.

[18] R. Chao and U. Tseng, "Parenting of Asians," in Handbook of Parenting, 2nd ed, M. H. Bornstein, Ed. Mahwah, NJ: Erlbaum, 2002, pp. 59-93.

[19] M. S. Stewart and M. H. Bond, "A critical look at parenting research from the mainstream: Problems uncovered while adapting Western research to non-Western cultures," British Journal of Developmental Psychology, vol. 20, pp. 379-392, 2002.

[20] R. Chao and S. Sue, "Chinese parental influence and their children's school success: A paradox in the literature on parental style," in Growing up the Chinese way, S. Lau, Ed., Hong Kong: The Chinese University Press, 1996, pp. 93-120.

[21] N. Foundation, "Changing adolescence programme: Time trends in parenting and outcomes for young people," London: Nuffield Foundation, 2009.

[22] K. A. Clarke-Stewart, "Historical shifts and underlying themes in ideas about rearing young children in the United States: where have 
we been? Where are we going?" Early Development and Parenting, vol. 7, pp. 101-117, 1998.

[23] M. C. Smith, P. C. V. Loon, N. DeFrates-Densch, and T. O. Schrader, "Content changes in parent education books for parents of adolescents," Family and Consumer Science Research Journal, vol. 27, no. 2, pp. 194-213, 1998.

[24] M. Radey and K. A. Randolph. "Parenting sources: How do parents differ in their efforts to learn about parenting?" Family Relations, vol. 58, pp. 536-548, 2009.

[25] S. Lau and L. K. Kwok, "Relationship of family environment to adolescents' depression and self-concept," Social Behavior and Personality, vol. 28, no. 1, pp. 41-50, 2000.

[26] D. T. L. Shek, "The relation of family functioning to adolescent psychological well-being, school adjustment, and problem behavior," Journal of Genetic Psychology, vol. 158, no. 4, pp. 467-479, 1997.

[27] D. T. L. Shek, T. Y. Lee, B. M. Lee, and J. Chow, "Perceived parental control and psychological well-being in Chinese adolescents in Hong Kong," International Journal of Adolescence Medicine and Health, vol. 18 , no. 3, pp. 535-545, 2006.

[28] D. Lam, "Parenting stress and anger: the Hong Kong experience," Child and Family Social Work, vol. 4, pp. 337-346, 1999.

[29] C. M. Lam, "Psychological stress and parenting behavior among Chinese families: Findings from a study on parent education for economically disadvantaged families," Social Indicators Research, vol. 100, pp. 451-462, 2011

[30] T. F. T. Leung and C. M. Lam, "The warrants of parenting: emotionality and reflexivity in economically disadvantaged families," Journal of Social Work Practice, Psychotherapeutic Approaches in Health, Welfare and the Community, vol. 23, no. 3, pp. 353-367, 2009.

[31] H. K. Fok and T. L. D. Shek, "A methodological critique of parenting research in Hong Kong," International Journal of Adolescent Medicine and Health, vol. 23, no. 2, pp. 93-99, 2011.

[32] G. W. Holden and M. J. Buck, "Parental attitudes toward childrearing," in Handbook of Parenting, M. H. Bornstein, Ed. London: Lawrence Erlbaum Associates, 2002.

[33] N. Schwarz, "Self-report: How the questions shape the answers," American Psychologist, vol. 54, pp. 93-105, 1999.

[34] D. Spence, Narrative: Truth and Historical Truth, New York: Norton, 1982.

[35] D. E. Polkinghorne, "Narrative knowing and the human sciences, Albany," New York: State University of New York Press, 1988.

[36] M. Cotazzi, "Narrative analysis," London: the Falmer Press, 1993.

[37] C. K. Riessman, Narrative Analysis, Newburry Park: Sage Publications, 1993.

[38] R. Atkinson, The Life Story Interview, Thousand Oaks: Sage, 1998.

[39] B. G. Glaser and A. L. Strauss, The Discovery of Grounded Theory: Strategies for Qualitive Research, New York: Aldine de Gruyte, 1967.

[40] D. M. Teti and P. M. Cole. "Parenting at risk: new perspectives, new approaches," Journal of Family Psychology, vol. 25, no. 5, pp. 625-634, 2011.

[41] C. M. Lam and W. M. Kwong, "Expert knowledge and pedagogical expectation: The 'paradox of empowerment' in parent education," Family relations, vol. 61, no.1, pp. 65-74, 2012.

[42] C. Honore, "Under Pressure: Rescuing our children from the culture of hyper-parenting," New York: HarperCollins Publishers, 2008.

[43] P. J. Winton, S. Sloop, and P. Rodriguez, "Parent education: A term whose time is past," Topics in Early Childhood Special Education, vol. 19, no. 3, pp. 157-161, 1999.

[44] J. B. Schor, "Born to buy: The commercialized child and the new consumer culture," New York, London, Toronto, Sydney: Scribner, 2004.

[45] K. Hirsh-Pasek, R. M. Golinkoff, and D. Eyer, "Einstein never used flash cards: How our children really learn and why they need to play more and memorize less," New York: Rodale, 2003.

[46] H. Wilson, "Brain science, early intervention and 'at risk' families: Implications to parents, professionals and social policy," Social Policy and Society, vol. 1, no. 3, pp. 191-202, 2002.
[47] T. L. Lui, "Who says parents are necessarily good persons?" Hong Kong: Step Forward Multi Media, 2002.

[48] M. Foucault, "Power/knowledge: Selected interviews and other writings," Pantheon, 1980.

[49] E. Freidson, "Professionalism reborn: Theory, prophecy, and policy," University of Chicago Press, 1994.

[50] C. M. Lam and W. M. Kwong, "Powerful parent educators and powerless parents: the 'empowerment paradox' in parent education," Journal of Social Work, 2014.

[51] L. H. Yuen, W. M. Kwong, and C. M. Lam, "Collaborative learning in group parent education: A case study of process and outcome," The International Journal of Early Childhood Learning, 2014.

[52] M. O'Brien and S. Penna, "Theorising welfare: Enlightenment and modern society," London, Thousand Oaks \& New Delhi: Sage, 1998

[53] Hong Kong Government, Social Welfare into the 1980's. Hong Kong: Government Printer, 1979.

[54] Education Commission. (1992). Education Commission Report NO.5. Hong Kong. [Online]. Available: https://www.edb.gov.hk/attachment/en/about-edb/publications-stat/m ajor-reports/ecr5_e.pdf

[55] Education Commission. (1999). Education Blueprint for the 21st Century - Review of Academic System: Aims of Education. Hong Kong. [Online]. Available https://www.e-c.edu.hk/en/publications_and_related_documents/on4 1st3a.html

[56] Education Commission. (2000). Reform Proposals for the Education System in Hong Kong, Hong Kong. [Online]. Available https://www.e-c.edu.hk/en/publications_and_related_documents/rf1. html

[57] Family Council. (2008). Paper FC 15/2008: Family Life Education, Hong Kong. [Online]. Available http://www.familycouncil.gov.hk/english/docs/ProgressWork_FC_1 5_2008.pdf

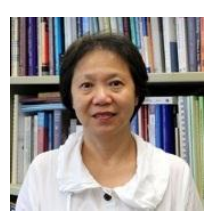

Ching-Man Lam is a professor of the Department of Social Work of The Chinese University of Hong Kong. She obtained her bachelor degree in social work at the Chinese University of Hong Kong, MSW at McGill University and the doctor of philosophy at the Wilfrid Laurier University, Canada. Her research interests are in the areas of parenting and parent education, marital and family therapy, family and parent empowerment, adolescence and family studies, and social work \& field education. She has published more than 70 refereed journal articles.

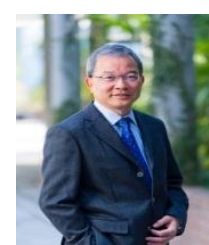

Wai-Man Kwong is a retired associate professor at the Department of Applied Social Sciences (later renamed Department of Social and Behavioural Sciences) of City University of Hong Kong. He completed his BSc and MSW at University of Hong Kong, M.Ed. at University of Toronto and Ph.D. at University of Bristol. His research interests including practice research, counsellor education, family and childhood resilience, parenting and parent education, and social work education.

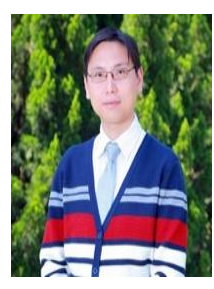

Siu-Ming To is an associate professor of the Department of Social Work, the Chinese University of Hong Kong. He obtained his bachelor, master and doctoral degree (doctor of philosophy in social welfare) at the Chinese University of Hong Kong. His research interests are in the areas of life and career development of young people and disadvantaged youth, parenting and parent education, youth empowerment, and refereed journal articles. program evaluation. He has published more than 40 